ARTICLE

\title{
Solid frustrated-Lewis-pair catalysts constructed by regulations on surface defects of porous nanorods of $\mathrm{CeO}_{2}$
}

Sai Zhang ${ }^{1, \star}$, Zheng-Qing Huang ${ }^{2, \star}$, Yuanyuan Ma, ${ }^{1,3}$ Wei Gao ${ }^{1}$, Jing $\mathrm{Li}^{1}$, Fangxian Cao ${ }^{1}$, Lin $\mathrm{Li}^{4}$, Chun-Ran Chang ${ }^{2} \&$ Yongquan $\mathrm{Qu}^{1,3}$

Identification on catalytic sites of heterogeneous catalysts at atomic level is important to understand catalytic mechanism. Surface engineering on defects of metal oxides can construct new active sites and regulate catalytic activity and selectivity. Here we outline the strategy by controlling surface defects of nanoceria to create the solid frustrated Lewis pair (FLP) metal oxide for efficient hydrogenation of alkenes and alkynes. Porous nanorods of ceria $\left(P N-\mathrm{CeO}_{2}\right)$ with a high concentration of surface defects construct new Lewis acidic sites by two adjacent surface $\mathrm{Ce}^{3+}$. The neighbouring surface lattice oxygen as Lewis base and constructed Lewis acid create solid FLP site due to the rigid lattice of ceria, which can easily dissociate $\mathrm{H}-\mathrm{H}$ bond with low activation energy of $0.17 \mathrm{eV}$.

\footnotetext{
${ }^{1}$ Center for Applied Chemical Research, Frontier Institute of Science and Technology and State Key Laboratory for Mechanical Behavior of Materials, Xi'an Jiaotong University, XiYi Hall, 99 Yanxiang Road, Xi'an, Shannxi 710049, China. ${ }^{2}$ Institute of Industrial Catalysis, School of Chemical Engineering and Technology, Xi'an Jiaotong University, Xi'an 710049, China. ${ }^{3}$ MOE Key Laboratory for Nonequilibrium Synthesis and Modulation of Condensed Matter, Xi'an Jiaotong University, Xi'an 710049, China. ${ }^{4}$ State Key Laboratory of Catalysis, Dalian Institute of Chemical Physics, Chinese Academy of Sciences, Dalian 116023, China. * These authors contributed equally to this work. Correspondence and requests for materials should be addressed to Y.Q. (email: yongquan@mail.xjtu.edu.cn) or to C.-R.C. (email: changcr@mail.xjtu.edu.cn).
} 
C atalytic hydrogenation of unsaturated substrates, a fundamental transformation process, is finding prolific industrial reactions, especially for petrochemistry ${ }^{1-3}$. Hydrogen activation by either transition metal complexes or metal-based heterogeneous catalysts have been well developed and successfully applied for various reactions ${ }^{4}$. Recently, frustrated Lewis pairs (FLPs), Lewis acids and bases that are sterically prevented from interaction to form Lewis acid-base adjuncts, can efficiently and cooperatively activate many small molecules (for example, $\mathrm{H}_{2}, \mathrm{CO}_{2}$, and $\mathrm{NO}$ ) and even strong $\mathrm{C}-\mathrm{H}$ bond for important catalytic reactions including hydrogenation, hydroamination and carbon dioxide reduction ${ }^{5-25}$.

However, molecular-based homogeneous FLP catalytic systems raise the difficulties in product purification and catalyst recovery. Therefore, the development of heterogeneous catalysts with FLP-like activity is extremely expected. Meanwhile, the combination of $\mathrm{Au}$ powder as Lewis acid and molecular Lewis bases (for example, imine and nitrile) successfully constructs the first example of semi-heterogeneous FLP catalytic system ${ }^{26}$. In this catalytic system, large quantity of Lewis acids and bases were required to avoid the formation of stable Lewis acid-base complexes. The semi-heterogeneous molecular sieves $\left./ \mathrm{B}_{(} \mathrm{C}_{6} \mathrm{~F}_{5}\right)_{3}$ FLPs deliver remarkable catalytic activity for hydrogenation of ketones and aldehydes ${ }^{27}$. Graphene synthesized by chemical exfoliation has been reported as efficient catalysts for hydrogen activation through an FLP-like behaviour ${ }^{28}$. When the Lewis acid and base sites are in an adequate distance, the activation of hydrogen becomes possible $e^{29-31}$. However, they require restricted demanding reaction conditions with long reaction time and a high $\mathrm{H}_{2}$ pressure of $30 \mathrm{bar}^{28}$. Formation of an FLP of the $\mathrm{Na}^{+} \mathrm{H}^{-}$/hydroxyl proton $\mathrm{O}\left(\mathrm{H}^{+}\right)$has been successfully demonstrated for $\mathrm{Pt}_{x} / \mathrm{NaY}$ zeolites by using in situ neutron diffraction and spectroscopic measurements ${ }^{32}$. Inspired by the catalytic mechanism of molecular FLP catalysts, it is also possible to develop novel heterogeneous FLP-like catalysts if independent Lewis acidic and basic species coexist in one material. Recently, Ozin and colleagues ${ }^{33-37}$ has reported that the surface FLP sites of $\operatorname{In}_{2} \mathrm{O}_{3-x}(\mathrm{OH})_{y}$ created by a Lewis acidic coordinately unsaturated surface indium site proximal to an oxygen vacancy and a Lewis basic surface hydroxide site showed the catalytic activity for the $\mathrm{CO}_{2}$ reduction by $\mathrm{H}_{2}$ in both experimental results and theoretical predictions. It provides a possible strategy to construct solid FLP sites in oxides by creating oxygen vacancy.

Nanostructured ceria is characterized with a large number of surface-bound defects that are primarily oxygen vacancy or $\mathrm{Ce}^{3+}$ species as active sites for heterogeneous catalysis ${ }^{38-43}$. In previous investigations, the catalytic ability of ceria is driven by the ability to switch between different oxidation states $\left(\mathrm{Ce}^{3+} / \mathrm{Ce}^{4+}\right.$ redox pair) accompanied with the storage and release of oxygen when the temperature is higher than $150{ }^{\circ} \mathrm{C}$ (ref. 44). At low temperature, the surface oxygen is less mobile and can be firmly held in the lattice matrix ${ }^{45,46}$. With these precedents in mind, the combination of the 'fixed' surface oxygen as Lewis base and surface defects as Lewis acid in ceria is similar to the sterically encumbered pairs of Lewis acids and bases for molecular FLP catalysts, if the surface Lewis acid and base are independent.

We choose ceria as another candidate to demonstrate the possibility to construct FLP sites due to its reversible $\mathrm{Ce}^{3+} / \mathrm{Ce}^{4+}$ redox pair and rich surface chemistry ${ }^{38}$. Ceria has been reported to exhibit the catalytic activity for the selective semi-hydrogenation of alkynes through the $\mathrm{H}_{2}$ activation by homolytic or heterolytic pathway and subsequent hydrogenation ${ }^{47-51}$. In general, a high temperature is required due to the inherent difficulty of ceria for $\mathrm{H}_{2}$ activation. Heterolytic (between lattice $\mathrm{Ce}^{4+}$ and $\mathrm{O}^{2-}$ ) pathway is considered as the pathway for $\mathrm{H}_{2}$ dissociation due to the relative low activation energy ${ }^{51}$. Hence, it is not surprise to observe the decreased hydrogenation activity of ceria with the increased surface defects 47,49 . Incapability for hydrogenation of alkenes and restricted reaction conditions for semi-hydrogenation of alkynes indicate the low hydrogenation activity of ceria.

In this work, solid FLP sites on $\mathrm{CeO}_{2}$ surface, which deliver a very high catalytic activity for hydrogenation of alkenes and alkynes with a wide scope under mild conditions $\left(T=100^{\circ} \mathrm{C}\right.$ and $P\left(\mathrm{H}_{2}\right)=1.0 \mathrm{MPa}$ ), have been successfully created by regulating their surface defects. The richness of surface defects is found to be the key for construction of a new surface Lewis acidic center by two adjacent reduced surface $\mathrm{Ce}$ atoms near an oxygen vacancy. The 'fixed' surface lattice oxygen as Lewis base and constructed Lewis acid have a large possibility to be close enough but independent due to the richness of surface defects and unique geometrical and electronic configurations, similar to the molecular-based FLPs. Porous nanorods of ceria $\left(P N-\mathrm{CeO}_{2}\right)$ with a large surface $\mathrm{Ce}^{3+}$ fraction of $30.8 \%$ associated with a high concentration of oxygen vacancy have been demonstrated as the solid metal oxide FLP catalyst with a low activation barrier of $0.17 \mathrm{eV}$ for $\mathrm{H}_{2}$ dissociation.

\section{Results}

Design strategy of solid FLP catalysts. Metal oxides possess the surface Lewis acid (metal cation) and Lewis base (oxygen anion), which form the Lewis acid-base adjuncts and deliver no FLP-like activity ${ }^{51,52}$. Fortunately, the surface defects induced by the reducible/oxidable valence states of metal cations associated with oxygen vacancy in metal oxides can create novel surface Lewis acidic sites and/or Lewis basic sites. The 'fixed' surface lattice atoms near the constructed surface defects in a close proximity may be unbonded, which can avoid the formation of classic Lewis acid-base adjuncts due to the rigid crystal lattice. Such a configuration may activate the small inert molecules such as $\mathrm{H}_{2}$ and $\mathrm{CO}_{2}$. Our hypothesis here is that the activation of inert molecules can be realized by rationally designed surface engineering and regulation on the structural defects of metal oxides to create novel FLP active sites. This possibility is illustrated by taking $\mathrm{CeO}_{2}$ as an example in view of both the geometrical and electronic configurations (Fig. 1).

Starting from the ideal $\mathrm{CeO}_{2}(110)$ facet, the surface $\mathrm{Ce}$ and $\mathrm{O}$ form Lewis acid-base adjuncts (Fig. 1a). Two kinds of surface configurations, $\mathrm{Ce}_{\mathrm{I}}-\mathrm{O}_{\mathrm{I}(\mathrm{a} \sim \mathrm{d})}$ and $\mathrm{Ce}_{\mathrm{I}^{-}}-\mathrm{O}_{\mathrm{II}}$, are identified on the ideal $\mathrm{CeO}_{2}(110)$ surface. $\mathrm{Ce}_{\mathrm{I}}$ and $\mathrm{O}_{\mathrm{I}(\mathrm{a} \sim \mathrm{d})}$ are adjacent and contiguous to each other, forming a classic Lewis acid-base adjunct, whereas the unbonded $\mathrm{Ce}_{\mathrm{I}}$ and $\mathrm{O}_{\text {IIc }}$ show a distance of $4.60 \AA$, which may deliver FLP-like activity. However, the electronic interactions between $\mathrm{Ce}_{\mathrm{I}}$ and its neighbouring $\mathrm{O}_{\mathrm{Ib}}$ will block the function of $\mathrm{Ce}_{\mathrm{I}}-\mathrm{O}_{\text {IIc }}$ pairs as shown in Fig. $1 \mathrm{~d}$. Therefore, the removal of oxygen atom directly linked with $\mathrm{Ce}_{\mathrm{I}}$ is the prerequisite to construct a pair of unbonded Lewis acid and base sites. When the $\mathrm{O}_{\mathrm{Ib}}$ atom is removed, two surface Ce atoms (including $\mathrm{Ce}_{\mathrm{I}}$ ) are reduced and one oxygen vacancy is produced, as demonstrated by the Bader charge population analysis of surface Ce (Supplementary Table 1). After structural relaxation, the $\mathrm{O}_{\mathrm{Ic}}$ near the oxygen vacancy immigrates to the middle of the $\mathrm{Ce}_{\mathrm{I}}$ and $\mathrm{Ce}_{\mathrm{II}}$, leading to $\mathrm{Ce}_{\mathrm{I}}$ being surrounded by three adjacent oxygen atoms (Fig. 1b). In this case, three types of configurations can be found including $\mathrm{Ce}_{\mathrm{I}}-\mathrm{O}_{\mathrm{Ia} / \mathrm{Id}}, \mathrm{Ce}_{\mathrm{I}}-\mathrm{O}_{\mathrm{Ic}}$ and $\mathrm{Ce}_{\mathrm{I}}-\mathrm{O}_{\mathrm{II} c}$, of which the $\mathrm{Ce}_{\mathrm{I}}-\mathrm{O}_{\mathrm{Ia} / \mathrm{Id}}$ and $\mathrm{Ce}_{\mathrm{I}}-\mathrm{O}_{\mathrm{Ic}}$ form classic Lewis acid-base adjuncts. The $\mathrm{Ce}_{\mathrm{I}}-\mathrm{O}_{\text {IIc }}$ with a distance of $4.72 \AA$ falls in the domain of solid FLPs to activate small molecules but is still hindered by $\mathrm{O}_{\mathrm{Ic} / \mathrm{Ia}}$ due to the electronic interaction between $\mathrm{Ce}_{\mathrm{I}}$ and $\mathrm{O}_{\text {Ic/Ia }}$ (Fig. 1e). When the second surface oxygen $\left(\mathrm{O}_{\mathrm{Ia}}\right)$ is removed, two oxygen vacancies and four reduced Ce cations (including $\mathrm{Ce}_{\mathrm{I}}$ and $\mathrm{Ce}_{\mathrm{II}}$ ) 


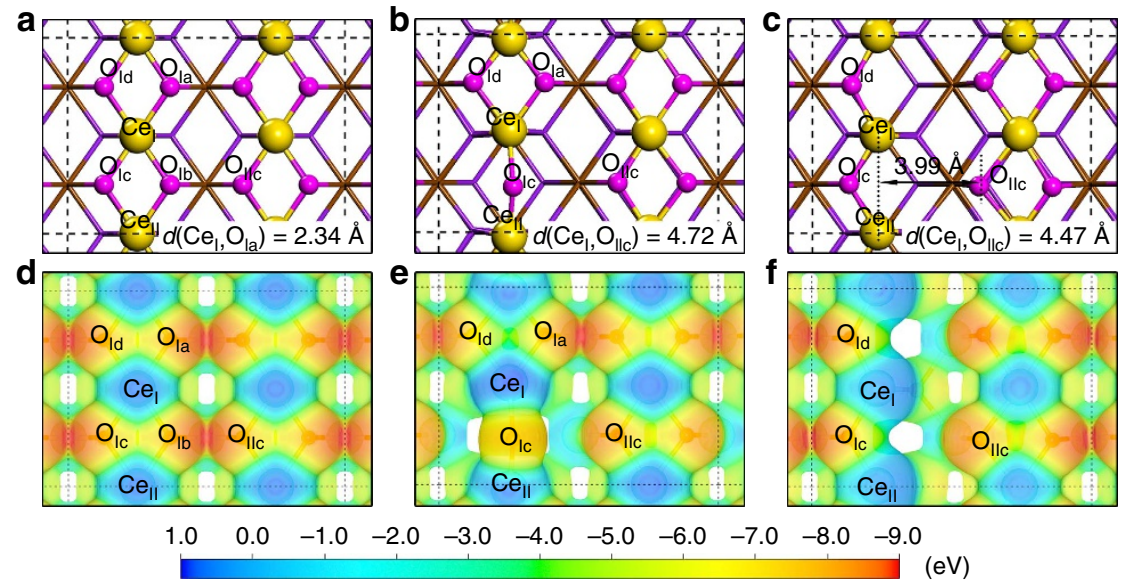

Figure 1 | Schematic images of concept for design of solid frustrated Lewis pairs in $\mathbf{C e O}_{\mathbf{2}}$ crystal structure. (a) Optimized structure of ideal $\mathrm{CeO}_{2}(110)$. (b) Optimized structure of $\mathrm{CeO}_{2}(110)$ with one oxygen vacancy. (c) Optimized structure of $\mathrm{CeO}_{2}(110)$ with two adjacent oxygen vacancies. (d) Electrondensity isosurface of ideal $\mathrm{CeO}_{2}(110)$. (e) Electron-density isosurface of $\mathrm{CeO}_{2}(110)$ with one oxygen vacancy. (f) Electron-density isosurface of $\mathrm{CeO}$ (110) with two oxygen vacancies. The electron-density isosurfaces are plotted at $0.01 \mathrm{e} \mathrm{bohr}^{-3}$. The colour bar represents the electrostatic potential scale.

are generated (Fig. 1c and Supplementary Table 1). The left oxygen $\mathrm{O}_{\mathrm{Ic}}$ and $\mathrm{O}_{\mathrm{Id}}$ will not migrate to the middle of two Ce cations. Thus, the reduced Ce cations $\left(\mathrm{Ce}_{\mathrm{I}}\right.$ and $\left.\mathrm{Ce}_{\mathrm{II}}\right)$ and surface lattice oxygen $\left(\mathrm{O}_{\mathrm{IIc}}\right)$ are independent Lewis acid and base, indicating that $\mathrm{Ce}_{\mathrm{I}}-\mathrm{O}_{\mathrm{IIc}}$ and $\mathrm{Ce}_{\mathrm{II}}-\mathrm{O}_{\text {IIc }}$ may act as the solid FLPs (Fig. 1c,f), similar to molecular FLPs. In addition, a special FLP-like active site of two adjacent reduced surface Ce sites $\left(\mathrm{Ce}_{\mathrm{I}}\right.$ and $\left.\mathrm{Ce}_{\mathrm{II}}\right)$ and lattice $\mathrm{O}_{\mathrm{IIc}}$ is constructed and denoted as $\left(\mathrm{Ce}_{\mathrm{I}}, \mathrm{Ce}_{\mathrm{II}}\right)-\mathrm{O}_{\text {IIc }}$ hereafter. Compared with $\mathrm{Ce}_{\mathrm{I}}-\mathrm{O}_{\text {IIc }}$ and $\mathrm{Ce}_{\mathrm{II}}-\mathrm{O}_{\text {IIc }}$ configurations, $\left(\mathrm{Ce}_{\mathrm{I}}, \mathrm{Ce}_{\mathrm{II}}\right)-\mathrm{O}_{\text {IIc }}$ with a shorter distance $(3.99 \AA)$ and stronger charge contraction by two adjacent reduced surface Ce cations is likely to deliver a higher capability to activate small molecules. On the other hand, the larger concentration of oxygen vacancy also increases the electron density of oxygen atoms (Bader charge analysis, Supplementary Table 1), suggesting the higher ability of oxygen to donate electrons. Bearing the above discussion in mind, it is possible to realize all-solid FLP catalysts of $\mathrm{CeO}_{2}$ by regulating the surface defects.

Similar to the $\mathrm{CeO}_{2}(110)$ surface, the solid FLPs can also be constructed by removing surface oxygen atoms of the $\mathrm{CeO}_{2}(100)$ surface. The surface oxygen atoms locate in the first atomic layer and surface cerium atoms sit in the second atomic layer on the ideal $\mathrm{CeO}_{2}(100)$ surface (Supplementary Figs 1a and 14b). The $\mathrm{Ce}_{\mathrm{I}}-\mathrm{O}_{\text {Ia }}$ pair forms a classic Lewis acid-base adjunct with a distance of only $2.19 \AA$. Although the $\mathrm{Ce}_{\mathrm{I}}-\mathrm{O}_{\text {Ic }}$ pair has a distance of $4.41 \AA$, it fails to be a FLP as the blocking of $\mathrm{O}_{\mathrm{Ib}}$ next to $\mathrm{Ce}_{\mathrm{I}}$ (Supplementary Fig. 1c). Removal of $\mathrm{O}_{\mathrm{Ib}}$ can construct a FLP site, $\left(\mathrm{Ce}_{\mathrm{I}}, \mathrm{Ce}_{\mathrm{II}}\right)-\mathrm{O}_{\mathrm{Ic}}$ with a distance of $3.95 \AA$ (Supplementary Fig. 1b,d), similar to the solid FLP catalyst on the reduced $\mathrm{CeO}_{2}(110)$ surface. However, the construction of surface FLP site cannot be realized by removing surface oxygen atoms on the $\mathrm{CeO}_{2}(111)$ facet. Similar to the ideal $\mathrm{CeO}_{2}(110)$ surface, two types of Lewis acid-base pairs, that is, $\mathrm{Ce}_{\mathrm{I}}-\mathrm{O}_{\mathrm{Ic}}$ and $\mathrm{Ce}_{\mathrm{II}}-\mathrm{O}_{\mathrm{IIc}}$, are classic Lewis acid-base pairs on the ideal $\mathrm{CeO}_{2}(111)$ surface. If one $\mathrm{O}$ atom $\left(\mathrm{O}_{\text {Ic }}\right.$ in Supplementary Fig. 2a) is removed (Supplementary Fig. 2b), the $\mathrm{O}_{\text {IIc }}$ atom is still surrounded by $\mathrm{Ce}_{\mathrm{II}}$ and $\mathrm{Ce}_{\text {III }}$ without the formation of FLP (Supplementary Fig. 2e). Similarly, when two $\mathrm{O}$ atoms $\left(\mathrm{O}_{\mathrm{Ib}}\right.$ and $\mathrm{O}_{\mathrm{Id}}$ in Supplementary Fig. 2a) are removed (Supplementary Fig. 2c), $\mathrm{O}_{\text {Ia }}$ and $\mathrm{Ce}_{\mathrm{I}}$ also cannot form FLPs owing to the blocking by $\mathrm{Ce}_{\mathrm{II}}{ }^{*}$ and $\mathrm{Ce}_{\mathrm{III}}{ }^{*}$ (Supplementary Fig. 2f). Therefore, the $\mathrm{CeO}_{2}$ nanostructures with the mainly exposed (110) and (100) facets may possess high catalytic hydrogenation activity rising from the formation of the solid FLPs.
Catalytic hydrogenation activity of $\mathbf{P N}-\mathrm{CeO}_{2}$. To explore the possibility of metal oxides as all-solid FLP catalysts, $\mathrm{PN}-\mathrm{CeO}_{2}$ with mainly exposed (110) and (100) facets, is selected as the model catalysts and hydrogenation of styrene is selected as a feature reaction. $\mathrm{PN}-\mathrm{CeO}_{2}$ has been previously reported with a high surface $\mathrm{Ce}^{3+}$ fraction (30.8\%) and a large concentration of oxygen vacancy ${ }^{53-56}$. Besides, the surface properties of $P N-\mathrm{CeO}_{2}$ can be effectively regulated by post-treatment with well preserved structural features, providing a platform to investigate the correlation between the hydrogenation activity of ceria and their surface properties.

$\mathrm{PN}-\mathrm{CeO}_{2}$ was synthesized through a two-step hydrothermal synthetic approach, in which nonporous nanorods (Supplementary Fig. 3) with the mixed phases of $\mathrm{Ce}(\mathrm{OH})_{3}$ and $\mathrm{CeO}_{2}$ was obtained in the first-step hydrothermal process at $100^{\circ} \mathrm{C}$ and porous nanorods with cubic fluorite structure were synthesized by dehydration/oxidation of precursor nanorods at the second hydrothermal treatment at $160^{\circ} \mathrm{C}$. Both bright-field and dark-field transmission electron microscopic (TEM) studies reveal a porous rod-like morphology with a dimension of $\sim 8 \times 60 \mathrm{~nm}$ (Fig. 2a,b). X-ray diffraction (XRD) analysis confirms the precursor nanorods undergo the dehydration of the $\mathrm{Ce}(\mathrm{OH})_{3}$ content being transformed into $\mathrm{CeO}_{2}$ at $160^{\circ} \mathrm{C}$ (Supplementary Figs $3 \mathrm{~b}$ and 4). High-resolution TEM (inset Fig. 2a) image of $P N-\mathrm{CeO}_{2}$ exhibits two kinds of lattice fringes of (220) and (200), which have respective inter-planar spacings of 0.191 and $0.275 \mathrm{~nm}$. Similar to previous reports, the nanorods preferentially grow along [110] direction and are enclosed by (220) and (200) planes ${ }^{57}$. Derived from dark-field TEM images, the average pore size is $2.94 \pm 0.78 \mathrm{~nm}$, which is similar as the average value of $2.2 \mathrm{~nm}$ obtained from the gas adsorption isotherms (Supplementary Fig. 5a,c,d). Surface area of $P N-\mathrm{CeO}_{2}$ determined by Brunauer-Emmett-Teller analysis is $122 \mathrm{~m}^{2} \mathrm{~g}^{-1}$ (Supplementary Fig. 5b).

Initially, optimization of the reaction conditions for hydrogenation reaction catalysed by $P N-\mathrm{CeO}_{2}$ is shown in Supplementary Table 2. Despite the catalytic activity of $P N-\mathrm{CeO}_{2}$ had been observed at a low temperature of $60^{\circ} \mathrm{C}$ and low $\mathrm{H}_{2}$ pressure of $0.2 \mathrm{MPa}$, an unsatisfied styrene conversion of $34.9 \%$ was delivered after $24 \mathrm{~h}$ reaction. Raising reaction temperature $\left(100^{\circ} \mathrm{C}\right)$ and $\mathrm{H}_{2}$ pressure $(1.0 \mathrm{MPa})$ realized the complete hydrogenation of styrene in $14 \mathrm{~h}$ successfully. Figure $2 \mathrm{c}$ shows time course of hydrogenation of styrene catalysed by 
a

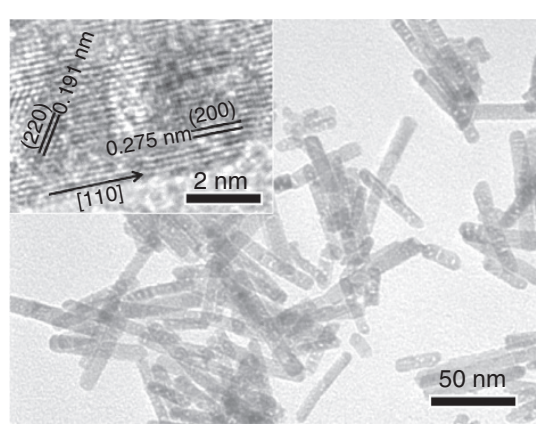

C

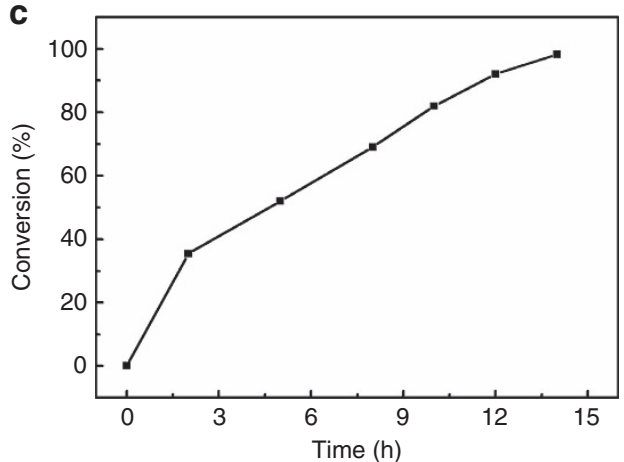

b
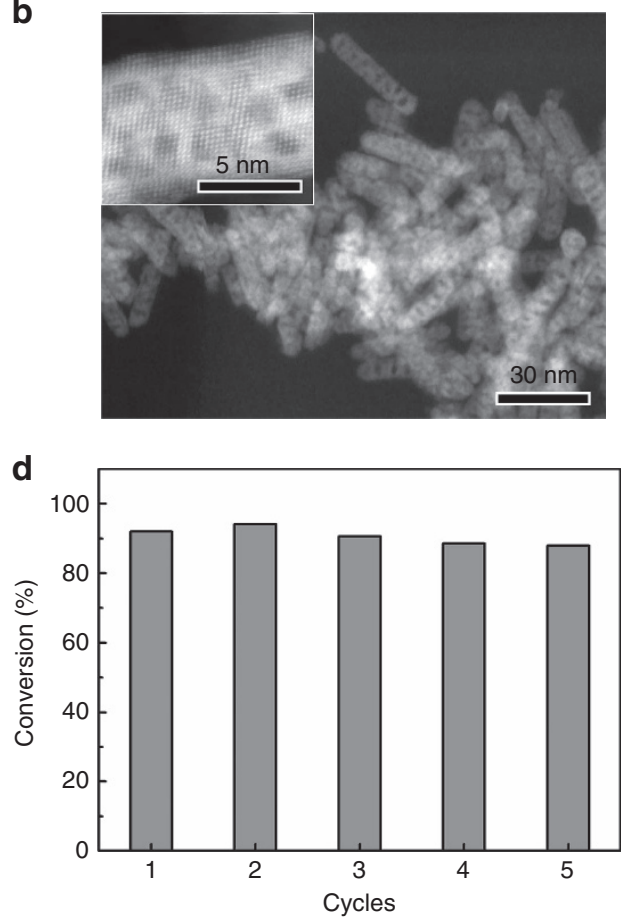

Figure 2 | Structural characterization and catalytic performance of $\mathbf{P N}-\mathbf{C e O}_{\mathbf{2}}$ catalysts for hydrogenation of styrene. (a) Bright-field TEM image of $P N-C_{2}$. Inset is the high resolution TEM image of $P N-C_{2} O_{2}$. (b) Dark-field TEM image of $P N-C_{2} O_{2}$. High resolution TEM image of inset displays a pore size of $2.94 \pm 0.78 \mathrm{~nm}$. (c) Time course of styrene conversion catalysed by $P N-C_{2} O_{2}$. (d) Recyclability of $P N-C_{2} O_{2}$ catalysts for hydrogenation of styrene. Reaction conditions: styrene $(1.0 \mathrm{mmol})$, toluene $(0.5 \mathrm{ml})$ and $\mathrm{PN}-\mathrm{CeO}_{2}(20.0 \mathrm{mg})$ at $100{ }^{\circ} \mathrm{C}$ and $1.0 \mathrm{MPa} \mathrm{H}_{2}$ pressure.

$P N-\mathrm{CeO}_{2}$. The reaction proceeded continuously to reach $98.2 \%$ conversion of styrene in $14 \mathrm{~h}$ and afford $>99.9 \%$ chemoselectivity towards ethylbenzene.

After catalytic hydrogenation reaction, $\mathrm{PN}-\mathrm{CeO}_{2}$ were recovered by centrifugation and washed with ethanol for three times. Before reuse, the spent $\mathrm{PN}-\mathrm{CeO}_{2}$ catalysts were treated at $220^{\circ} \mathrm{C}$ for $4 \mathrm{~h}$ under the argon protection. Afterwards, $\mathrm{PN}-\mathrm{CeO}_{2}$ can achieve five-time recyclability without any obvious catalytic degradation (Fig. 2d). The unaltered morphology, unchanged phase and almost no changed surface $\mathrm{Ce}^{3+}$ fraction of the spent $P N-\mathrm{CeO}_{2}$ illustrate their structural and catalytic stability during hydrogenation reactions (Supplementary Fig. 6).

Catalytic screening of various metal oxides. Derived from the previous studies on the semi-hydrogenation of alkynes by ceria $^{47}, P N-\mathrm{CeO}_{2}$ with a high concentration of surface defects should inactive or even inert for hydrogenation of styrene. To understand the high catalytic activity of $\mathrm{PN}^{-\mathrm{CeO}_{2}}$ in the current work, the catalytic activity of various metal oxides including acidic oxides, basic oxides and transition metal oxides for hydrogenation of styrene were also investigated under $100^{\circ} \mathrm{C}$ and $1.0 \mathrm{MPa}$ for $14 \mathrm{~h}$. As presented in Fig. 3a, the typical acidic oxides $\left(\mathrm{SiO}_{2}, \mathrm{Al}_{2} \mathrm{O}_{3}\right.$ and $\left.\mathrm{SnO}_{2}\right)$ delivered a very poor catalytic activity with styrene conversions below $1.4 \%$. Poor catalytic activity of basic oxides $(\mathrm{CaO}, \mathrm{MgO}$ and $\mathrm{ZnO})$ was also observed. Meanwhile, the styrene conversions obtained from other common transition metal oxides, $\mathrm{CuO}, \mathrm{Fe}_{2} \mathrm{O}_{3}, \mathrm{NiO}, \mathrm{MoO}_{3}$ and $\mathrm{Co}_{3} \mathrm{O}_{4}$, were below $0.8 \%$, indicating their inertness for the hydrogenation of alkenes under the operated conditions.

Control experiments (Fig. 3a) indicated that the hydrogenation reaction of styrene could not happen in the absence of $\mathrm{PN}-\mathrm{CeO}_{2}$, indicating the nature catalytic ability of $\mathrm{PN}^{-\mathrm{CeO}_{2}}$. The major difference between $P N-\mathrm{CeO}_{2}$ and other metal oxides is the coexistence of Lewis acidic and basic sites in high concentrations for $\mathrm{PN}-\mathrm{CeO}_{2}$. Therefore, the survey of metal oxides for hydrogenation of styrene indicates that the absence of either acidic or basic sites on the surface of metal oxides results in near complete deactivation for the hydrogenation of alkenes.

To further confirm the necessity of the co-existence of Lewis acidic and basic sites of $\mathrm{PN}-\mathrm{CeO}_{2}$ in current catalytic system, hydrogenation of styrene was performed in the presence of other molecular Lewis acid or base during the catalytic process. The Lewis base pyridine and Lewis acid pyrrole as common molecules are generally used to confirm the presence of Lewis acidic and basic sites for metal oxides, respectively. As a strong base pyridine (strong acid pyrrole) can be able to absorb on the Lewis acidic (Lewis basic) sites of $\mathrm{PN}-\mathrm{CeO}_{2}$ immediately, when they are added to the reaction solution. Therefore, the FLPs can be effectively blocked by the pyridine and pyrrole molecule. As shown in Fig. 3b, addition of trace amount of either Lewis base pyridine or Lewis acid pyrrole completely terminated the hydrogenation reactions due to the blockage of surface Lewis acidic or basic sites by those small molecules, respectively, similar to that of molecular FLPs $^{58,59}$. Trace amount of pyridine/pyrrole molecules were adsorbed on the surface Lewis acidic/basic sites of $\mathrm{CeO}_{2}$, leading to a low possibility for the formation of surface FLP sites in the aspect of population of adjacent surface $\mathrm{Ce}^{3+}$. The blockage of either Lewis basic sites or Lewis acidic sites of $\mathrm{PN}-\mathrm{CeO}_{2}$ leads to the deactivated hydrogenation of alkenes, revealing that the coexistence of Lewis acidic and basic sites on the surface of $\mathrm{PN}-\mathrm{CeO}_{2}$ are essential to activate $\mathrm{H}-\mathrm{H}$ bond and achieve high activity in the current system.

Role of surface defects of $\mathrm{PN}-\mathrm{CeO}_{2}$ for hydrogenation. For the semi-hydrogenation of alkynes by ceria, hydrogen dissociative adsorption on surface oxygen leads to the formation of two 

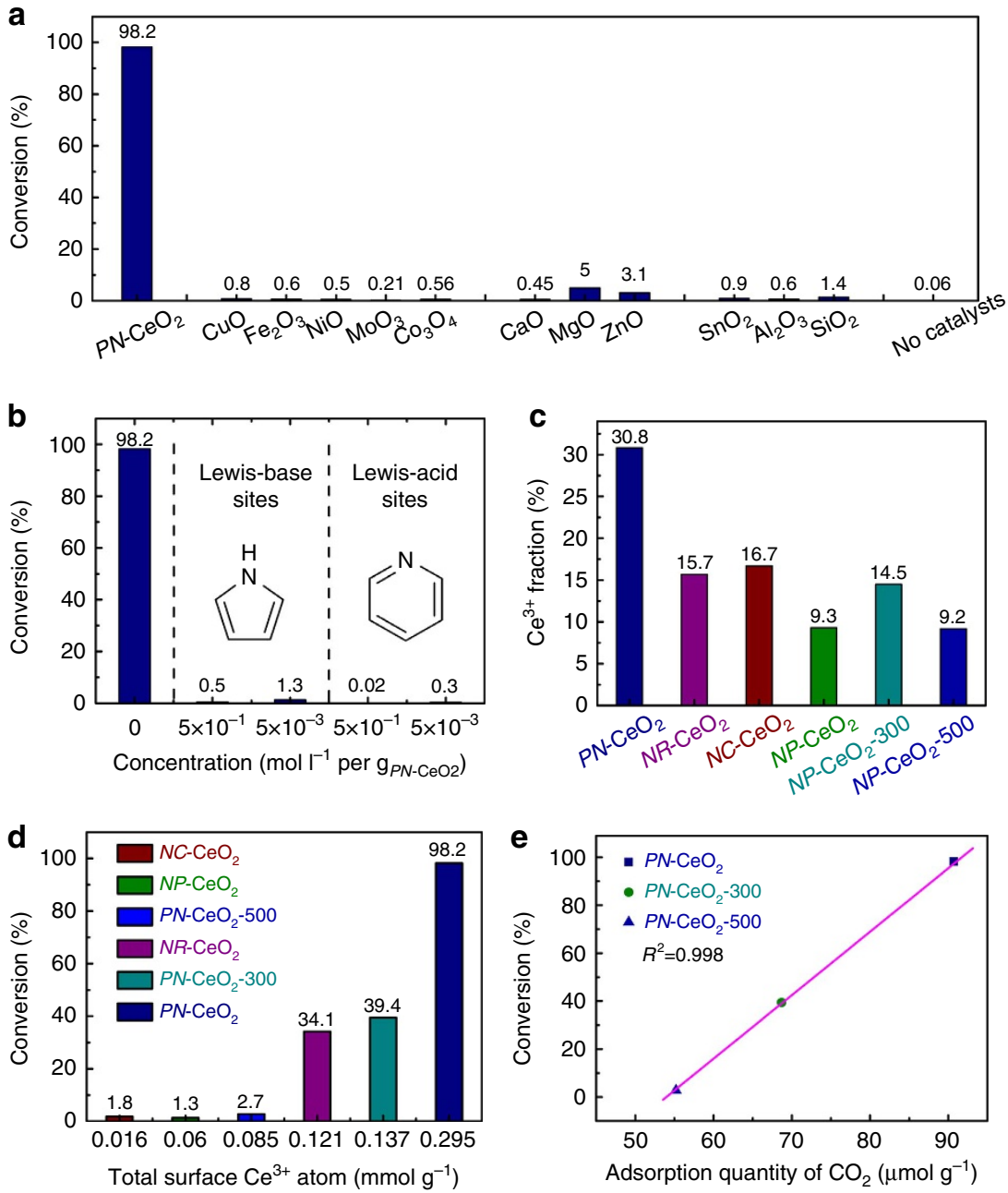

Figure 3 | Mechanism investigations on hydrogenation activity of $\mathbf{P N}-\mathbf{C e O}_{\mathbf{2}}$ (a) Catalytic activity of various metal oxides for hydrogenation of styrene. (b) Influences of molecular Lewis-base or Lewis-acid on the catalytic activity of $P N-\mathrm{CeO}_{2}$ for hydrogenation of styrene. (c) Catalytic activity of nanoceria for hydrogenation of styrene. (d) Effects of the total surface $\mathrm{Ce}^{3+}$ atom number for hydrogenation of styrene. (e) Correlation between conversion of styrene and adsorption quantity of $\mathrm{CO}_{2}$ on $\mathrm{CeO}_{2}$ catalyst. Reaction conditions: styrene $(1.0 \mathrm{mmol})$, toluene $(0.5 \mathrm{ml})$ and catalysts $(20.0 \mathrm{mg})$ at $100{ }^{\circ} \mathrm{C}$ and $1.0 \mathrm{MPa}$ $\mathrm{H}_{2}$ pressure for $14 \mathrm{~h}$.

surface $-\mathrm{OH}$ groups and dissociation of $\mathrm{C}-\mathrm{H}$ bond of $\mathrm{R}-\mathrm{C} \equiv \mathrm{C}-\mathrm{H}$ on the adjacent surface $\mathrm{Ce}$ and $\mathrm{O}$ atoms ${ }^{49}$. In those studies, three points were outlined: (1) the obtained alkenes cannot be further reduced into alkanes; (2) experimental results suggest that the hydrogen activation process is the rate-limiting step due to the poor ability of ceria to cleave $\mathrm{H}-\mathrm{H}$ bond; (3) the catalytic activity of ceria can be significantly decreased in the presence of large amount of surface defects. Followed by the literature reports, $\mathrm{PN}-\mathrm{CeO}_{2}$ with a high surface concentration of oxygen vacancy should deliver a poor catalytic activity for hydrogenation reactions. In fact, $\mathrm{PN}-\mathrm{CeO}_{2}$ indeed shows a very high catalytic activity for styrene hydrogenation, suggesting a different catalytic mechanism for the current work. Besides, both alkenes and alkynes can be reduced by $\mathrm{PN}-\mathrm{CeO}_{2}$ under much mild conditions (see Discussion below), also revealing an alternative catalytic pathway for hydrogen activation and subsequent hydrogenation.

To explore the roles of surface defects of ceria, hydrogenation of styrene was also performed for ceria nanoparticles $\left(\mathrm{NP}-\mathrm{CeO}_{2}\right)$ with a surface $\mathrm{Ce}^{3+}$ fraction of 9.3\% (Supplementary Fig. 7), ceria nanocubes $\left(\mathrm{NC}-\mathrm{CeO}_{2}\right)$ with a surface $\mathrm{Ce}^{3+}$ fraction of 16.7\% (Supplementary Fig. 8) and non-porous ceria nanorods
$\left(\mathrm{NR}-\mathrm{CeO}_{2}\right)$ with a surface $\mathrm{Ce}^{3+}$ fraction of $15.7 \%$ (Supplementary Fig. 9). The conversions of styrene were only $1.3 \%, 1.8 \%$ and $34.1 \%$ for $\mathrm{NP}-\mathrm{CeO}_{2}, \mathrm{NC}-\mathrm{CeO}_{2}$ and $\mathrm{NR}-\mathrm{CeO}_{2}$ under the identical reaction conditions of those catalysed by $\mathrm{PN}-\mathrm{CeO}_{2}$ for $14 \mathrm{~h}$, respectively (Fig. 3d). The surface area of $98 \mathrm{~m}^{2} \mathrm{~g}^{-1}$ for $\mathrm{NR}-\mathrm{CeO}_{2}$ is close to that of $\mathrm{PN}-\mathrm{CeO}_{2}$ of $122 \mathrm{~m}^{2} \mathrm{~g}^{-1}$ (Supplementary Table 3), indicating surface area is not the critical factor to determine their difference in their catalytic activity for hydrogenation of alkenes. The high consistence between the surface $\mathrm{Ce}^{3+}$ fractions and the catalytic activity of ceria reveals that the hydrogenation activity of ceria is determined by the abundance of the surface defect sites.

As predicted from the theoretical calculations, it is also possible to create the surface FLP sites on $\mathrm{CeO}_{2}(100)$ surface. However, the catalytic activity of $\mathrm{NC}-\mathrm{CeO}_{2}$ was much lower than that of $\mathrm{PN}-\mathrm{CeO}_{2}$. Considering the small surface area of $\mathrm{NC}-\mathrm{CeO}_{2}$, we also performed the hydrogenation of styrene by $200 \mathrm{mg} \mathrm{NC}-\mathrm{CeO}_{2}$ with the comparable surface area to that of $20 \mathrm{mg} P N-\mathrm{CeO}_{2}$ under the identical conditions. A very low styrene conversion of $5.3 \%$ was observed, which could be attributed to the low concentration of surface defects of $\mathrm{NC}-\mathrm{CeO}_{2}$ with a $\mathrm{Ce}^{3+}$ fraction of $16.7 \%$. The results further confirm that the 
concentration of surface defects is the main factor to construct large amount of surface FLP sites without regard to the morphology of $\mathrm{CeO}_{2}$ catalysts.

Hydrogenation performance of $\mathrm{NR}-\mathrm{CeO}_{2} \quad(20 \mathrm{mg})$ and $\mathrm{NC}-\mathrm{CeO}_{2}(200 \mathrm{mg})$ catalysts suggested that the catalytic activity of FLP sites on $\mathrm{CeO}_{2}(110)$ was higher than that of $\mathrm{CeO}_{2}(100)$ with similar surface $\mathrm{Ce}^{3+}$ fractions (Fig. 3c,d). It can be attributed to the different steric configuration of FLP sites on $\mathrm{CeO}_{2}(110)$ and $\mathrm{CeO}_{2}(100)$. Both the acidic and basic sites of the constructed FLP sites on $\mathrm{CeO}_{2}(110)$ are in the top atomic layer (Fig. 1c,f and Supplementary Fig. 14a), whereas the basic sites (O atoms) on $\mathrm{CeO}_{2}(100)$ are in the top atomic layer with the second atomic layer of the acidic sites (Ce atoms) (Supplementary Figs 1d and 14b). Both two configurations can effectively activate hydrogen molecule. However, styrene can encounter less steric hindrance when reacting with the intermediate of heterolysis of $\mathrm{H}_{2}$ at the FLP sites on $\mathrm{CeO}_{2}(110)$. Besides, due to the high surface energy, oxygen atoms of $\mathrm{CeO}_{2}(100)$ is more prone to diffuse on surface than that of $\mathrm{CeO}_{2}(110)^{60}$. This diffuse of oxygen atoms (basic sites) can break the steric encumbered structures of FLP sites, leading to the decrease in activity of FLP sites or even the formation of classic acid-base adduct. Thus, the FLP sites on $\mathrm{CeO}_{2}(100)$ are less stable than those on $\mathrm{CeO}_{2}(110)$, indicating that the stability of FLP sites could be another factor in the decrease of activity on $\mathrm{CeO}_{2}(100)$ surface.

The surface $\mathrm{Ce}^{3+}$ fractions of $\mathrm{PN}-\mathrm{CeO}_{2}$ were effectively reduced from $30.8 \%$ of as-synthesized catalysts to 14.5 and $9.2 \%$ (Fig. $3 \mathrm{c}$ and Supplementary Fig. 10), when $\mathrm{PN}-\mathrm{CeO}_{2}$ was treated at $300{ }^{\circ} \mathrm{C}$ (obtained $\mathrm{PN}-\mathrm{CeO}_{2}-300$ catalysts) and $500{ }^{\circ} \mathrm{C}$ (obtained $\mathrm{PN}-\mathrm{CeO}_{2}-500$ catalysts) in air for $8 \mathrm{~h}$, respectively. The calcinated $\mathrm{PN}-\mathrm{CeO}_{2}$ preserved the porous morphology (Supplementary Fig. 11), as well as their surface areas (Supplementary Table 3). After calcination, the obtained $\mathrm{PN}-\mathrm{CeO}_{2}$ catalysts were immediately used for hydrogenation of styrene under the same conditions. The $39.4 \%$ and $2.7 \%$ conversions of styrene were yielded with $P N-\mathrm{CeO}_{2}-300$ and $P N-C_{2} \mathrm{O}_{2}-500$, respectively. The decreased catalytic activity can only be attributed to their decreased concentration of surface oxygen vacancy due to the high temperature annealing at 300 and $500^{\circ} \mathrm{C}$ in air.

On the other hand, the $\mathrm{PN}-\mathrm{CeO}_{2}$ was reduced under $10 \%$ $\mathrm{H}_{2} / \mathrm{Ar}$ at $200{ }^{\circ} \mathrm{C}$ for $2 \mathrm{~h}$ and then transferred from the reducing atmosphere to the hydrogenation system immediately. The exposure of the reduced $P N-\mathrm{CeO}_{2}$ to air was controlled $5 \mathrm{~min}$ to minimize the re-oxidation of the reduced catalysts. The catalytic activity for reduced $\mathrm{PN}-\mathrm{CeO}_{2}$ also enhanced from $69.1 \%$ to $86.4 \%$ after $8 \mathrm{~h}$ reaction (Supplementary Fig. 12). The enhanced catalytic activity can be attributed to the increased concentration of surface oxygen vacancy, leading to an increased possibility to construct more surface FLP sites. Therefore, the parallel experiments further strengthen the evidence linking the concentration of surface oxygen vacancy of $P N-\mathrm{CeO}_{2}$ with their catalytic activity for hydrogenation of alkenes.

The decreased hydrogenation activity of $P N-\mathrm{CeO}_{2}-300$ and $P N-\mathrm{CeO}_{2}-500$ can be further revealed from the temperatureprogrammed hydrogen desorption $\left(\mathrm{H}_{2}\right.$-TPD) tests. All $\mathrm{PN}-\mathrm{CeO}_{2}$ catalysts were exposed to $\mathrm{H}_{2}$ at $50{ }^{\circ} \mathrm{C}$ and the weakly physisorbed hydrogen was removed by flushing Ar for $20 \mathrm{~min}$. A desorption peak at $190^{\circ} \mathrm{C}$ was observed for all $\mathrm{PN}_{-} \mathrm{CeO}_{2}$ catalysts (Supplementary Fig. 13), indicating a strong interaction between $\mathrm{H}_{2}$ and $\mathrm{PN}-\mathrm{CeO}_{2}$. With the increase of calcination temperature, the decreased peak intensities demonstrated the reduced amount of activated hydrogen on $\mathrm{PN}-\mathrm{CeO}_{2}-300$ and $\mathrm{PN}-\mathrm{CeO}_{2}-500$. Therefore, the decreased catalytic activity of the calcined $\mathrm{PN}-\mathrm{CeO}_{2}$ was delivered for styrene hydrogenation.
Mechanism investigations. All control experiments strongly suggest that the coexistence of Lewis acidic and basic sites plays extremely important roles in activating hydrogen at mild conditions and realising their high catalytic activity for hydrogenation reactions. The results are totally different to the catalytic mechanism of the semi-hydrogenation of alkynes by ceria $^{47-49}$. In Fig. 1, we have illustrated that it is possible to create FLP active sites through regulations on the surface defects of $\mathrm{CeO}_{2}(110)$. In general, the key features of organic molecules FLP catalysts are defined as the independent Lewis acid and base in the presence of sterically substituents on Lewis acid and base to preclude the formation of the classical Lewis acid-base adducts $^{30,61}$. Addition of any other small Lewis acid or base molecules results in the formation of adducts and completely blocks the catalytic activity of FLP catalysts during the catalytic process $9,12,28$. On the basis of the known essentiality of molecular FLP catalysts and a strong correlation between the hydrogenation activity and surface properties of $\mathrm{PN}-\mathrm{CeO}_{2}$ with coexistence of Lewis acid and base in current system, it's logical to rationalize the $P N-\mathrm{CeO}_{2}$ as all-solid FLP catalysts. The analogous aspects of molecular FLP catalysts and $P N-\mathrm{CeO}_{2}$ are listed: (1) independent surface Lewis acidic and basic sites of $\mathrm{PN}-\mathrm{CeO}_{2}$ (Fig. 1c); (2) close proximity $(4 \sim 5 \AA)$ between surface Lewis acidic site and basic site for activation or splitting of small molecules; and (3) completely quenched hydrogenation activity with addition of other Lewis acids or bases.

To support the aforementioned conclusions, DFT calculations using the Vienna Ab-initio Simulation Package ${ }^{62-64}$ were performed to investigate the adsorption and activation of hydrogen on the $\mathrm{CeO}_{2}(110)$ surface. For ideal $\mathrm{CeO}_{2}(110)$ (Supplementary Fig. 14a), hydrogen molecule prefers to be adsorbed at the top site of $\mathrm{Ce}_{\mathrm{I}}$ (Fig. 4a) or classic acid-base site (Fig. 4b) with weak adsorption energies of $-0.06 \mathrm{eV}$, in consistence with previous studies ${ }^{65,66}$. The $\mathrm{H}-\mathrm{H}$ bond length of the weakly adsorbed $\mathrm{H}_{2}$ is 0.75 and $0.76 \AA$ for the two adsorption configurations, respectively. These values are close to that of gas phase $\mathrm{H}_{2}(0.75 \AA)$, suggesting that $\mathrm{H}_{2}$ is difficult to be activated on ideal $\mathrm{CeO}_{2}(110)$. The Bader charge populations of the physisorbed $\mathrm{H}_{2}$ (Fig. 4a,b) further indicate that $\mathrm{H}_{2}$ is slightly polarized and hardly activated on ideal $\mathrm{CeO}_{2}(110)$. With one oxygen vacancy constructed on $\mathrm{CeO}_{2}(110)$, the adsorption and activation of $\mathrm{H}_{2}$ is still poor on both $\mathrm{Ce}_{\mathrm{I}}-\mathrm{O}_{\text {Ic }}$ (Fig. $4 c,-0.06 \mathrm{eV}$ ) and $\mathrm{Ce}_{\mathrm{I}}-\mathrm{O}_{\text {IIc }}$ sites (Fig. $4 \mathrm{~d},-0.04 \mathrm{eV}$ ), which is further evidenced by the long distance $(\sim 3.0 \AA)$ between $\mathrm{H}_{2}$ and $\mathrm{CeO}_{2}(110)$ surface and the similar $\mathrm{H}-\mathrm{H}$ bond length of adsorbed $\mathrm{H}_{2}$ to that of gas-phase $\mathrm{H}_{2}$. For the surface with two adjacent oxygen vacancies, $\mathrm{H}_{2}$ preferentially adsorbs at the created solid FLP site $\left(\mathrm{Ce}_{\mathrm{I}}, \mathrm{Ce}_{\mathrm{II}}\right)-\mathrm{O}_{\text {IIc }}$ (Fig. $4 \mathrm{f}$ ) rather than on the top site of the unsaturated $\mathrm{Ce}$ atom (Fig. 4e). The results reveal the easy activation of $\mathrm{H}_{2}$ molecule at the site of $\left(\mathrm{Ce}_{\mathrm{I}}, \mathrm{Ce}_{\mathrm{II}}\right)-\mathrm{O}_{\text {IIc }}$ : (1) a relatively larger adsorption energy of $\mathrm{H}_{2}$ of $-0.13 \mathrm{eV}$ (Fig. 4f). (2) A significantly elongated $\mathrm{H}-\mathrm{H}$ bond length of $0.80 \AA$. (3) A shorter distance between $\mathrm{H}_{2}$ and the $\mathrm{CeO}_{2}(110)$ than those in other adsorption configurations (Fig. 4a-e). The distance between one hydrogen atom of $\mathrm{H}_{2}$ and the base site of solid FLPs is only $1.89 \AA$. (4) A larger polarization of $\mathrm{H}-\mathrm{H}$ bond due to the electrostatic interactions between the FLPs and $\mathrm{H}_{2}$, as indicated in the Bader charge of $-0.16 e$ and $+0.11 e$ for two hydrogen atoms (Fig. 4f). The aforementioned aspects strongly suggest that the novel solid FLP site constructed by two Ce cations and one $\mathrm{O}$ anion is more effective in $\mathrm{H}_{2}$ adsorption and activation than the classic acid-base adjuncts.

To further confirm the high activity of such a constructed solid FLP site towards the activation of small molecules, the dissociative activation of $\mathrm{H}_{2}$ is investigated on the ideal $\mathrm{CeO}_{2}(110)$ and reduced $\mathrm{CeO}_{2}(110)$ surface in the presence of 

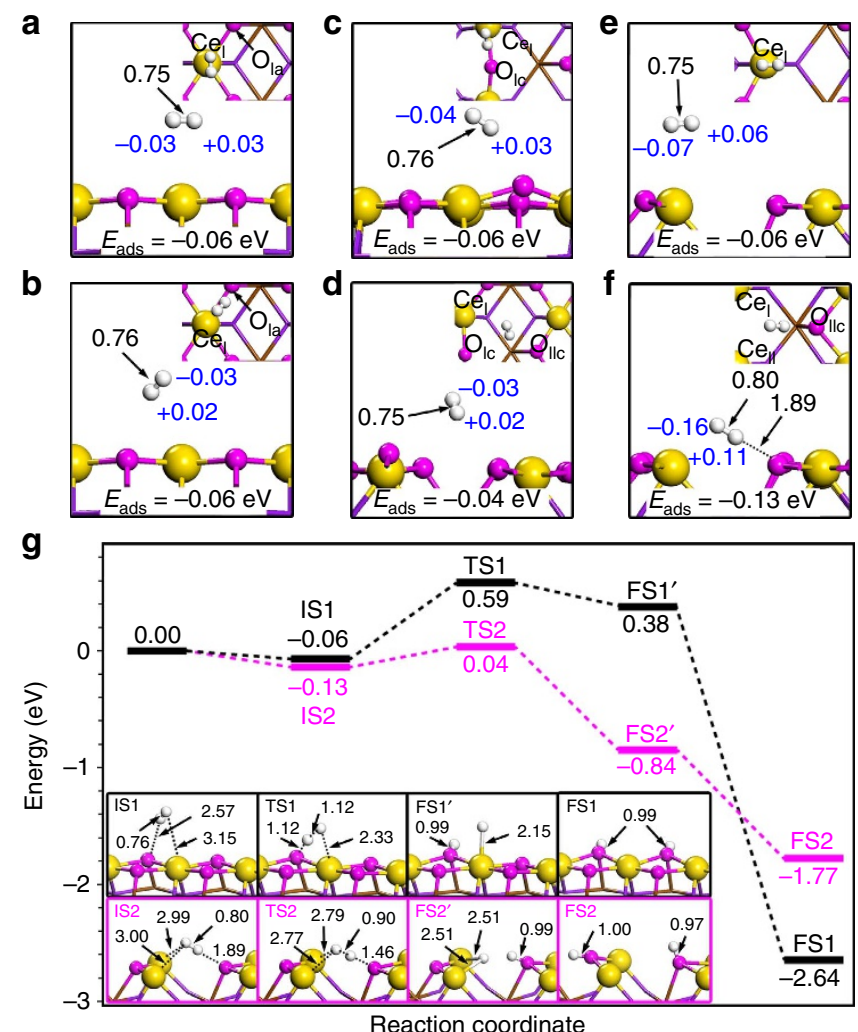

Figure 4 | The $\mathrm{H}_{2}$ adsorption and dissociation pathways on the surface of $\mathbf{P N}-\mathrm{CeO}_{2}$. The optimized structures of $\mathrm{H}_{2}$ adsorption on (a) $\mathrm{Ce}_{1}$ atom of ideal $\mathrm{CeO}_{2}(110)$; (b) $\mathrm{Ce}_{1}-\mathrm{O}_{\text {la }}$ pair of ideal $\mathrm{CeO}_{2}(110)$; (c) $\mathrm{Ce}_{1}-\mathrm{O}_{\mathrm{lc}}$ pair of $\mathrm{CeO}_{2}(110)$ with one oxygen vacancy; (d) $\mathrm{Ce}_{1}-\mathrm{O}_{\text {IIc }}$ pair of $\mathrm{CeO}_{2}(110)$ with one oxygen vacancy; (e) $\mathrm{Ce}_{1}$ atom of $\mathrm{CeO}_{2}(110)$ with two oxygen vacancies; and $(\mathbf{f})\left(\mathrm{Ce}_{1}, \mathrm{Ce}_{\|}\right)-\mathrm{O}_{\text {IIc }}$ pair of $\mathrm{CeO}_{2}(110)$ with two oxygen vacancies in both top (inset) and side views. The adsorption energies $\left(E_{\text {ads }}\right)$, the bond distances (in $\AA$ ) colored in black, and the Bader charge population (in e) colored in blue are also shown. (g) Energy profiles for $\mathrm{H}_{2}$ dissociation on ideal $\mathrm{CeO}_{2}(110)$ in black curve and $\mathrm{CeO}_{2}(110)$ with two oxygen vacancies in red curves. The optimized structures of initial states (IS), transition states (TS) and final states (FS) are labeled with bond distance (in $\AA$ ). The zero energy reference corresponds for the sum energy of $\mathrm{H}_{2}$ in the gas phase and the corresponding clean $\mathrm{CeO}_{2}$ surfaces.

$\left(\mathrm{Ce}_{\mathrm{I}}, \mathrm{Ce}_{\mathrm{II}}\right)-\mathrm{O}_{\text {IIc }}$. From the energy profile depicted by Fig. $4 \mathrm{~g}$ (black curve), the dissociation of $\mathrm{H}_{2}$ on ideal $\mathrm{CeO}_{2}(110)$ starts from a physisorbed state (IS1) and surpasses an activation barrier of $0.65 \mathrm{eV}$ to reach a dissociated state (FS1'). In FS1', the dissociated hydrogen bound to Ce site is meta-stable and readily diffuses to nearby surface oxygen, leading to the formation of a more stable FS1. The $\mathrm{H}_{2}$ dissociation on $\mathrm{CeO}_{2}(110)$ with the solid FLP active sites experiences a similar process, which also starts from a physisorbed state. Noticeably, the dissociation barrier is only $0.17 \mathrm{eV}$ on the constructed FLP site, which is $0.48 \mathrm{eV}$ lower than that on ideal $\mathrm{CeO}_{2}(110)$. Moreover, the dissociation of $\mathrm{H}_{2}$ on solid FLPs (from IS2 to FS2') is exothermic by $0.71 \mathrm{eV}$ in contrast to the endothermic energy $(0.44 \mathrm{eV}$, from IS1 to FS1') on ideal $\mathrm{CeO}_{2}(110)$. Both kinetic and thermodynamic results suggest that the dissociative activation of $\mathrm{H}_{2}$ is more favourable on the reduced $\mathrm{CeO}_{2}(110)$ with active FLP sites. The dissociated hydrogen anchored at the Ce site (FS2') can immigrate to an adjacent oxygen to form FS2 with an exothermic energy of $0.93 \mathrm{eV}$. It is worth noting that FS2 is less stable than FS1, despite two hydrogen atoms are both adsorbed at surface oxygen in two configurations. The calculations suggest that the $\mathrm{O}-\mathrm{H}$ bond in FS2 is weaker than that in FS1. The weakness of $\mathrm{O}-\mathrm{H}$ bond is attributed to the enhanced basicity of oxygen on the reduced $\mathrm{CeO}_{2}(110)$, which is detrimental to the adsorption of $\mathrm{H}$ according to the rules of Lewis acid-base pairs on oxide surfaces ${ }^{67}$. Fortunately, the less stable $\mathrm{O}-\mathrm{H}$ bonds are expected to benefit the subsequent hydrogenation reactions.

Derived from DFT calculations, $\mathrm{CeO}_{2}$ nanorods with a high concentration of surface oxygen defects deliver a high possibility to create surface $\left(\mathrm{Ce}_{\mathrm{I}}, \mathrm{Ce}_{\mathrm{II}}\right)-\mathrm{O}_{\mathrm{IIc}}$ FLP sites, yield an enhanced capability of dissociation of $\mathrm{H}_{2}$ and improve their catalytic activity for hydrogenation of styrene. The calculation results (Fig. 4) are highly consistent with experiments (Fig. 3), supporting the solid FLP-like activity of $P N-\mathrm{CeO}_{2}$ regulated and constructed by the surface oxygen defects as illustrated in Fig. 1. To further confirm this conclusion, the correlation between catalytic activity and the concentration of the surface oxygen vacancy of $\mathrm{CeO}_{2}$ were studied through the TPD of $\mathrm{CO}_{2}$ on the various $P N-\mathrm{CeO}_{2}-T$ catalysts. The annealed $P N-\mathrm{CeO}_{2}$ at 300 and $500{ }^{\circ} \mathrm{C}$ exhibited the identical morphological features to those of as-synthesized $P N-\mathrm{CeO}_{2}$ (Supplementary Fig. 11). Importantly, the $P N-\mathrm{CeO}_{2}-300\left(120 \mathrm{~m}^{2} \mathrm{~g}^{-1}\right)$ and $P N-\mathrm{CeO}_{2}-500$ $\left(117 \mathrm{~m}^{2} \mathrm{~g}^{-1}\right)$ showed similar surface areas to that of as-synthesized $\mathrm{PN}^{-\mathrm{CeO}_{2}}\left(122 \mathrm{~m}^{2} \mathrm{~g}^{-1}\right)$. Thus, such a system provides a straightforward way to understand the correlations between the acidity/basicity of $\mathrm{PN}-\mathrm{CeO}_{2}$ and their catalytic activity.

In previous reports, $\mathrm{CO}_{2}$ as a Lewis acid can bind with $\mathrm{O}^{2-}$ surface ions forming carbonate species with various anchoring structures (bridged, bidentate, monodentate and polydentate) ${ }^{59}$. Furthermore, the presence of oxygen vacancy on $\mathrm{CeO}_{2}$ surface can make a strong interaction with $\mathrm{CO}_{2}$ and thus enhance its surface basicity ${ }^{58}$. The surface adsorption quantity of $\mathrm{CO}_{2}$ is the highest on $P N-\mathrm{CeO}_{2}\left(90.7 \mu \mathrm{mol} \mathrm{g}{ }^{-1}\right)$, followed by $P N-\mathrm{CeO}_{2}-300$ $\left(68.7 \mu \mathrm{mol} \mathrm{g}^{-1}\right)$, and the least on $P N-\mathrm{CeO}_{2}-500\left(55.2 \mu \mathrm{molg}^{-1}\right)$ from the $\mathrm{CO}_{2}$-TPD results (Supplementary Fig. 15 and Supplementary Table 4). The reduced surface basic sites mainly derived from the obviously decreased medium and strong basic sites, which indicated the decreased amount of surface oxygen vacancy. Meanwhile, the conversions of styrene showed a near linear decrease with the decreased adsorption quantity of $\mathrm{CO}_{2}$ on various $\mathrm{PN}-\mathrm{CeO}_{2}$ catalysts (Fig. 3e, $R^{2}=0.998$ ). Results further demonstrate the importance of the surface abundance of defects in $\mathrm{CeO}_{2}$ catalysts to construct the surface FLP sites once more.

The correlation between the concentration of oxygen vacancy and their catalytic activity is further investigated with Raman spectra analysis. The concentration of oxygen vacancy is indexed by the ratio of the integrated peak area under the bands at $460 \mathrm{~cm}^{-1}$ (vibrational mode of $\mathrm{CeO}_{2}$ fluorite structure) and $600 \mathrm{~cm}^{-1}$ (oxygen vacancy) of the Raman spectra of $P N-\mathrm{CeO}_{2}$ annealed at various temperatures (Supplementary Fig. 16) ${ }^{28}$. The decrease in the $\mathrm{A}_{600} / \mathrm{A}_{460}$ with the increased calcination temperature indicates a decrease in the number of oxygen vacancy, as well as the surface $\mathrm{Ce}^{3+}$ fraction. Thus, high temperature treatment on $\mathrm{PN}-\mathrm{CeO}_{2}$ leads to the decrease in the number of FLPs sites. Therefore, it is not surprising to observe an obviously decreased conversion of styrene with $\mathrm{PN}-\mathrm{CeO}_{2}-300$ and $P N-\mathrm{CeO}_{2}-500$; even they have almost the same surface areas (Supplementary Table 3).

The conversion of styrene as a function of total surface $\mathrm{Ce}^{3+}$ species (Fig. 3d) and the concentration of oxygen vacancy (Fig. 3e and Supplementary Fig. 16b) indicate that the abundance of surface defects is important for the construction of FLP active sites on $\mathrm{PN}-\mathrm{CeO}_{2}$. The high concentration of surface defects introduces a high possibility to form the surface FLP sites as shown in Fig. 1c. Both theoretical calculations and experimental 
Table 1 | Scope of $\mathrm{PN}-\mathrm{CeO}_{2}$ for catalytic hydrogenation of alkenes*

$\begin{array}{cccccc}\text { Pressure } & \text { Time Conversion } & \text { Selectivity } \\ (\%)\end{array}$

GC, gas chromatography; MS, mass spectrometry.

${ }^{*}$ Reaction condition: $\mathrm{PN}-\mathrm{CeO}_{2}(2 \mathrm{mg})$, toluene $(0.5 \mathrm{ml})$, substrate $(1 \mathrm{mmol})$ at $100{ }^{\circ} \mathrm{C}$ under various $\mathrm{H}_{2}$ pressures. The substrate conversion and product selectivity were determined by $\mathrm{GC}-\mathrm{MS}$ and $\mathrm{GC}$ with $\mathrm{m}$-xylene as the internal standard.

results illustrate that the FLP active sites in $\mathrm{PN}-\mathrm{CeO}_{2}$ are created by regulations on their surface properties.

Hydrogenation scope of alkenes. The scope of hydrogenation reactions catalysed by $\mathrm{PN}-\mathrm{CeO}_{2}$ was demonstrated in Table 1 . When the electron-donating groups of methyl $\left(-\mathrm{CH}_{3}\right)$, tertiary butyl $\left(-\mathrm{C}\left(\mathrm{CH}_{3}\right)_{3}\right)$ and methoxy $\left(-\mathrm{OCH}_{3}\right)$ were introduced in styrene, the reactant conversions of $99.1,98.1$ and $99 \%$ were yielded under $0.6,0.6$ and $1.0 \mathrm{MPa} \mathrm{H}_{2}$ pressure, respectively (Entry 1, 2 and 3). However, the catalytic hydrogenation activity of $\mathrm{PN}-\mathrm{CeO}_{2}$ was obviously decreased in the presence of electrondrawing groups in the substrates. The introduction of $-\mathrm{Br}$ and $-\mathrm{Cl}$ afforded the conversions of $98.5 \%$ and $79.5 \%$ under $1.0 \mathrm{MPa}$ $\mathrm{H}_{2}$ pressure for $20 \mathrm{~h}$, respectively (Entry 4 and 5). It can be attributed to the decreased electronic density of vinyl group in the presence of electron-drawing groups in benzene ring. The hydrogenation of cyclooctene into cyclooctane reached a conversion of $90.5 \%$ under $1.0 \mathrm{MPa} \mathrm{H}_{2}$ pressure for $20 \mathrm{~h}$ (Entry 6). When the $\mathrm{H}$ at $\alpha$ or $\beta$ site of vinyl is replace by other groups, the catalytic activity of $\mathrm{PN}-\mathrm{CeO}_{2}$ for hydrogenation of vinyl is also decreased due to steric hindrance. Compared to $56.3 \%$ conversion of $\alpha$-methylstyrene under $1.0 \mathrm{MPa}_{2}$ for $20 \mathrm{~h}$ (Entry 7), trans-stibene and cis-stilbene only reached $10.3 \%$ and $8.9 \%$ conversions under the same reaction conditions, respectively (Entry 8 and 9).

In light of both experimental and theoretical investigations, the introduction of oxygen vacancy is very important in the formation of FLP active sites for $\mathrm{PN}-\mathrm{CeO}_{2}$. When alkenes include oxygen-containing groups, the blockage of the surface FLP active sites on $\mathrm{PN}-\mathrm{CeO}_{2}$ may happen due to the strong adsorption of oxygen at the surface defects. Thus, the catalytic activity of $\mathrm{PN}-\mathrm{CeO}_{2}$ for those molecules can be reduced or completely depressed. As shown in Table 1 (Entry 10 and 11), trans-cinnamaldehyde and allylacetone in the presence of formyl or ketone groups only yielded very low reactant conversions of $21.7 \%$ and $12.8 \%$, respectively, despite a high chemoselectivity for olefine products $(>99.9 \%)$. Owing to the strong interaction between $-\mathrm{OH}$ or $-\mathrm{NO}_{2}$ groups and surface defects of $\mathrm{PN}-\mathrm{CeO}_{2}$, the activity of FLPs was shielded with 4-hydroxystyrene and 4-nitrostyrene, affording very low conversions ( $<6 \%$, Entry 12 and 13). There results further support the solid FLP catalytic behaviour of $\mathrm{PN}-\mathrm{CeO}_{2}$ for hydrogenation reactions.

Hydrogenation scope of alkynes. Ceria has shown the ability to selectively semi-hydrogenated alkynes into olefins ${ }^{49}$. Herein, hydrogenation of various alkynyl substrates was also evaluated with $\mathrm{PN}-\mathrm{CeO}_{2}$ (Table 2). For hydrogenation of phenylacetylene, the conversion was increased from 55.8 to $100 \%$ with the increase of $\mathrm{H}_{2}$ pressure from 1.0 to $3.0 \mathrm{MPa}$ within $14 \mathrm{~h}$ (Entries 14 and 15). However, the selectivity towards styrene was decreased from 95.8 to $32.6 \%$ (Entries 14 and 15). By contrast, the selectivity of ethylbenzene was increased from 4.2 to $67.4 \%$ (Entry 14 and 15). Only ethylbenzene was obtained with the extended reaction time (Entry 16). The presence of electron-donating methyl group in phenylacetylene yielded $100 \%$ conversion under $3.0 \mathrm{MPa} \mathrm{H}_{2}$ pressure but a poor chemoselectivity of $75.2 \%$ into 4-methylstyrene (Table 2, Entry 17). For 4-methoxy phenylacetylene, similar catalytic behaviour was observed with a $84.7 \%$ selectivity of olefin for the conversion of $100 \%$ under $3.0 \mathrm{MPa} \mathrm{H}_{2}$ pressure at $100^{\circ} \mathrm{C}$ (Entry 18). Introducing the electron-drawing substituents on phenylacetylene such as $-\mathrm{Br}$ and $-\mathrm{Cl}$, the catalytic activity was reduced, as the low conversions of $50 \%$ and $13.7 \%$ were yielded for 4-bromo phenylacetylene and 4-chloro phenylacetylene under a $\mathrm{H}_{2}$ pressure of $3.0 \mathrm{MPa}$ and a temperature of $100^{\circ} \mathrm{C}$ for $14 \mathrm{~h}$, respectively (Entries 19 and 20). For 4-phenyl-1-butyne, 38.9\% conversion and $100 \%$ selectivity towards olefin products were achieved under 3.0 $\mathrm{MPa} \mathrm{H}_{2}$ pressure for $14 \mathrm{~h}$ reaction (Entry 21). 
Table 2 | Scope of $\mathrm{PN}^{-\mathrm{CeO}_{2}}$ for catalytic hydrogenation of alkynes ${ }^{\star}$.

Entry Substrate $\begin{gathered}\begin{array}{c}\text { Pressure } \\ (\mathrm{MPa})\end{array} \\ (\mathrm{h})\end{gathered}$

GC, gas chromatography; MS, mass spectrometry.

*Reaction condition: $\mathrm{PN}-\mathrm{CeO}_{2}(20 \mathrm{mg})$, toluene $(0.5 \mathrm{ml})$, substrate $(1 \mathrm{mmol})$ at $100{ }^{\circ} \mathrm{C}$ under various $\mathrm{H}_{2}$ pressures. The substrate conversion and product selectivity were determined by $\mathrm{GC}-\mathrm{MS}$ and $\mathrm{GC}$ with $\mathrm{m}$-xylene as the internal standard.

The catalytic activity of $\mathrm{PN}-\mathrm{CeO}_{2}$ was also decreased when the alkynes in the presence of the steric substituents. Under $3.0 \mathrm{MPa}$ $\mathrm{H}_{2}$ pressure, hydrogenation of diphenylacetylene only afforded a $13.8 \%$ conversion after $20 \mathrm{~h}$ reaction (Entry 22 ). The products of hydrogenation were a mixture of trans-stilbene and cis-stilbene with the chemoselectivity of $51.3 \%$ and $48.7 \%$, respectively (Entry 23).

In summary, we design all-solid metal oxide FLP catalysts through regulations on the surface properties of ceria. As demonstrated by both experimental and theoretical results, $P N-\mathrm{CeO}_{2}$ with a high concentration of surface defects exhibits the FLP catalytic behaviour for the efficient hydrogenation of alkenes and alkynes with a wide scope. The high density of surface-bound defects is critical to generate the independent surface Lewis acidic and basic sites, construct the surface FLP pair of $\left(\mathrm{Ce}_{\mathrm{I}}, \mathrm{Ce}_{\mathrm{II}}\right)-\mathrm{O}_{\mathrm{IIc}}$ (Fig. 1c) and improve their capability for $\mathrm{H}_{2}$ activation with a low activation barrier of $0.17 \mathrm{eV}$. The capability to hydrogenate alkynes into alkanes further confirms the high hydrogenation activity of $\mathrm{PN}-\mathrm{CeO}_{2}$. The current progress provides a new concept on the structurally correlated catalytic activity of ceria for hydrogenation reactions, which is important for the modern catalyst design. With the ease of preparation, such $\mathrm{PN}-\mathrm{CeO}_{2}$ as the active components in various hydrogenation reactions may be envisioned and so are their ultimate industrial applications.

\section{Methods}

Preparation of $\mathbf{P N}-\mathbf{C e O}_{2}$ catalysts. Aqueous solutions of $\mathrm{Ce}\left(\mathrm{NO}_{3}\right)_{3} \cdot 6 \mathrm{H}_{2} \mathrm{O}$ $(1.736 \mathrm{~g} \text { in } 10 \mathrm{ml} \text { of deionized water })^{53}$ and $\mathrm{NaOH}(19.2 \mathrm{~g}$ in $70 \mathrm{ml}$ of deionized water) were mixed slowly. With continuous stirring, the mixture was aged for $30 \mathrm{~min}$ before the reaction continued at $100^{\circ} \mathrm{C}$ for $24 \mathrm{~h}$ in a temperature-controlled electric oven. The reaction mixture was then cooled naturally to room temperature.
The products were collected by centrifugation, thoroughly washed with deionized water, and then air-dried at $60^{\circ} \mathrm{C}$. Hydrothermal treatment of this precursor product at $160^{\circ} \mathrm{C}$ for $12 \mathrm{~h}$ afforded the formation of $\mathrm{PN}-\mathrm{CeO}_{2}$.

Characterizations. The catalysts were characterized by powder XRD. The XRD patterns with diffraction intensity versus $2 \theta$ were recorded in a Shimadzu X-ray diffractometer (Model 6000) using $\mathrm{Cu} K_{\alpha}$ radiation. TEM studies were conducted on the Hitachi HT-7700 with an accelerating voltage of $120 \mathrm{kV}$. High-resolution and dark-field TEM images were acquired from the Tecnai G2 F20 S-twin TEM at $200 \mathrm{kV}$. Surface area was measured by $\mathrm{N}_{2}$ physisorption (Micromeritics, ASAP 2020 HD88) based on Brunauer-Emmet-Teller method. X-ray photoelectron spectroscopy were acquired using a Thermo Electron Model K-Alpha with $\mathrm{Al} K_{\alpha}$ as the excitation source.

Catalytic hydrogenation reactions. For a typical catalytic reaction, $1.0 \mathrm{mmol}$ of substrate and $20.0 \mathrm{mg}$ of catalysts were mixed in $0.5 \mathrm{ml}$ of toluene. The reactions were performed in the autoclave charged with hydrogen with various pressures at the desired reaction temperature. The products were analysed by gas chromatography-mass spectrometry and gas chromatography with $\mathrm{m}$-xylene as the internal standard.

Data availability. Data supporting the findings of this study are available within the article (and its Supplementary Information files) and from the corresponding author on reasonable request.

\section{References}

1. Higman, C. \& Tam, S. Advances in coal gasification, hydrogenation, and gas treating for the production of chemicals and fuels. Chem. Rev. 114, 1673-1708 (2014).

2. Johnson, N. B., Lennon, I. C., Moran, P. H. \& Ramsden, J. A. Industrial-scale synthesis and applications of asymmetric hydrogenation catalysts. Acc. Chem. Res. 40, 1291-1299 (2007).

3. Vispute, T. P., Zhang, H., Sanna, A., Xiao, R. \& Huber, G. W. Renewable chemical commodity feedstocks from integrated catalytic processing of pyrolysis oils. Science 330, 1222-1227 (2010). 
4. Wang, W., Wang, S., Ma, X. \& Gong, J. Recent advances in catalytic hydrogenation of carbon dioxide. Chem. Soc. Rev. 40, 3703-3727 (2011).

5. Stephan, D. W. \& Gerhard, E. Frustrated Lewis pair chemistry: development and perspectives. Angew. Chem. Int. Ed. Engl. 54, 6400-6441 (2015)

6. Stephan, D. W. Frustrated Lewis pairs: from concept to catalysis. Acc. Chem Res. 48, 306-316 (2015)

7. Stephan, D. W. Frustrated Lewis pairs. J. Am. Chem. Soc. 137, 10018-10032 (2015).

8. Morozova, V., Mayer, P. \& Berionni, G. Scope and mechanisms of frustrated Lewis pair catalyzed hydrogenation reactions of electron-deficient $\mathrm{C}=\mathrm{C}$ double bonds. Angew. Chem. Int. Ed. Engl. 54, 14508-14512 (2015).

9. Mo, Z. et al. Facile reversibility by design: tuning small molecule capture and activation by single component frustrated Lewis pairs. J. Am. Chem. Soc. 137, 12227-12230 (2015).

10. Stephan, D. W. Frustrated Lewis pairs: a metal-free landmark. Nat. Chem. 6, 952-953 (2014)

11. Pereira, J. C. et al. Reaction of a bridged frustrated Lewis pair with nitric oxide: a kinetics study. J. Am. Chem. Soc. 136, 513-519 (2014).

12. Voicu, D. et al. Microfluidic studies of $\mathrm{CO}_{2}$ sequestration by frustrated Lewis pairs. J. Am. Chem. Soc. 136, 3875-3880 (2014).

13. Borger, J. E., Ehlers, A. W., Lutz, M., Slootweg, J. C. \& Lammertsma, K. Stabilization and transfer of the transient $\left[\mathrm{Mes}^{*} \mathrm{P}_{4}\right]^{-}$butterfly anion using $\mathrm{BPh}_{3}$. Angew. Chem. Int. Ed. Engl. 56, 613-617 (2015).

14. Chen, J. \& Chen, E. Y. Elusive silane-alane complex [Si-HAl]: isolation, characterization, and multifaceted frustrated Lewis pair type catalysis. Angew. Chem. Int. Ed. Engl. 54, 6842-6846 (2015).

15. Chernichenko, K. et al. Intramolecular frustrated Lewis pair with the smallest boryl site: reversible $\mathrm{H}_{2}$ addition and kinetic analysis. Angew. Chem. Int. Ed. Engl. 54, 1749-1753 (2015).

16. Hansmann, M. M. et al. Cyclopropanation/carboboration reactions of enynes with $\mathrm{B}\left(\mathrm{C}_{6} \mathrm{~F}_{5}\right)_{3}$. J. Am. Chem. Soc. 137, 15469-15477 (2015).

17. Légaré, M.-A., Courtemanche, M.-A., Rochette, É. \& Fontaine, F.-G. Metal-free catalytic C-H bond activation and borylation of heteroarenes. Science 349, 513-516 (2015)

18. Eisenberger, P., Bestvater, B. P., Keske, E. C. \& Crudden, C. M. Hydrogenations at room temperature and atmospheric pressure with mesoionic carbenestabilized borenium catalysts. Angew. Chem. Int. Ed. Engl. 54, 2467-2471 (2015).

19. Oestreich, M., Hermeke, J. \& Mohr, J. A unified survey of Si-H and H-H bond activation catalysed by electron-deficient boranes. Chem. Soc. Rev. 44, 2202-2220 (2015)

20. Chernichenko, K. et al. A frustrated-Lewis-pair approach to catalytic reduction of alkynes to cis-alkenes. Nat. Chem. 5, 718-723 (2013).

21. Mahdi, T. \& Stephan, D. W. Frustrated Lewis pair catalyzed hydroamination of terminal alkynes. Angew. Chem. Int. Ed. Engl. 52, 12418-12421 (2013).

22. Courtemanche, M. A., Legare, M. A., Maron, L. \& Fontaine, F. G. Reducing $\mathrm{CO}_{2}$ to methanol using frustrated Lewis pairs: on the mechanism of phosphineborane-mediated hydroboration of $\mathrm{CO}_{2}$. J. Am. Chem. Soc. 136, 10708-10717 (2014).

23. Kalz, K. F., Brinkmeier, A., Dechert, S., Mata, R. A. \& Meyer, F. Functional model for the $[\mathrm{Fe}]$ hydrogenase inspired by the frustrated Lewis pair concept. J. Am. Chem. Soc. 136, 16626-16634 (2014).

24. Lawrence, E. J., Oganesyan, V. S., Hughes, D. L., Ashley, A. E. \& Wildgoose, G. G. An electrochemical study of frustrated Lewis pairs: a metal-free route to hydrogen oxidation. J. Am. Chem. Soc. 136, 6031-6036 (2014).

25. Liedtke, R. et al. Frustrated Lewis pair modification by 1,1-carboboration: disclosure of a phosphine oxide triggered nitrogen monoxide addition to an intramolecular P/B frustrated Lewis pair. J. Am. Chem. Soc. 136, 9014-9027 (2014).

26. Lu, G. et al. Gold catalyzed hydrogenations of small imines and nitriles: enhanced reactivity of $\mathrm{Au}$ surface toward $\mathrm{H}_{2}$ via collaboration with a Lewis base. Chem. Sci. 5, 1082-1090 (2014).

27. Mahdi, T. \& Stephan, D. W. Facile protocol for catalytic frustrated Lewis pair hydrogenation and reductive deoxygenation of ketones and aldehydes. Angew. Chem. Int. Ed. Engl. 54, 8511-8514 (2015).

28. Primo, A., Neatu, F., Florea, M., Parvulescu, V. \& Garcia, H. Graphenes in the absence of metals as carbocatalysts for selective acetylene hydrogenation and alkene hydrogenation. Nat. Commun. 5, 5291 (2014).

29. Stephan, D. W. \& Erker, G. Frustrated Lewis pairs: metal-free hydrogen activation and more. Angew. Chem. Int. Ed. Engl. 49, 46-76 (2010).

30. Eros, G. et al. Expanding the scope of metal-free catalytic hydrogenation through frustrated Lewis pair design. Angew. Chem. Int. Ed. Engl. 49, 6559-6563 (2010)

31. Wang, X., Kehr, G., Daniliuc, C. G. \& Erker, G. Internal adduct formation of active intramolecular $\mathrm{C}_{4}$-bridged frustrated phosphane/borane Lewis pairs. J. Am. Chem. Soc. 136, 3293-3303 (2014).

32. Lee, H. et al. Formation of frustrated Lewis pairs in $\mathrm{Pt}_{\mathrm{x}}$-loaded zeolite $\mathrm{NaY}$. Angew. Chem. Int. Ed. Engl. 54, 13080-13084 (2015).
33. Ghuman, K. K. et al. Illuminating $\mathrm{CO}_{2}$ reduction on frustrated Lewis pair surfaces: investigating the role of surface hydroxides and oxygen vacancies on nanocrystalline $\operatorname{In}_{2} \mathrm{O}_{3-\mathrm{x}}(\mathrm{OH})_{\mathrm{y}}$. Phys. Chem. Chem. Phys. 17, 14623-14635 (2015).

34. Ghuman, K. K. et al. Photoexcited surface frustrated Lewis pairs for heterogeneous photocatalytic $\mathrm{CO}_{2}$ reduction. J. Am. Chem. Soc. 138, 1206-1214 (2016).

35. Ghuman, K. K. et al. Surface analogues of molecular frustrated Lewis pairs in heterogeneous $\mathrm{CO}_{2}$ hydrogenation catalysis. ACS Catal. 6, 5764-5770 (2016).

36. He, L. et al. Spatial separation of charge carriers in $\operatorname{In}_{2} \mathrm{O}_{3-\mathrm{x}}(\mathrm{OH})_{\mathrm{y}}$ nanocrystal superstructures for enhanced gas-phase photocatalytic activity. ACS Nano 10, 5578-5586 (2016).

37. Ghoussoub, M., Yadav, S., Ghuman, K. K., Ozin, G. A. \& Singh, C. V. Metadynamics-biased ab initio molecular dynamics study of heterogeneous $\mathrm{CO}_{2}$ reduction via surface frustrated Lewis pairs. ACS Catal. 6, 7109-7117 (2016).

38. Vivier, L. \& Duprez, D. Ceria-based solid catalysts for organic chemistry. ChemSusChem 3, 654-678 (2010).

39. Wang, X., Liu, D., Li, J., Zhen, J. \& Zhang, H. Clean synthesis of $\mathrm{Cu}_{2} \mathrm{O} @ \mathrm{CeO}_{2}$ core@shell nanocubes with highly active interface. NPG Asia Mater. 7, e158 (2015).

40. Paier, J., Penschke, C. \& Sauer, J. Oxygen defects and surface chemistry of Ceria: quantum chemical studies compared to experiment. Chem. Rev. 113, 3949-3985 (2013).

41. Corma, A., Atienzar, P., Garcia, H. \& Chane-Ching, J. Y. Hierarchically mesostructured doped $\mathrm{CeO}_{2}$ with potential for solar-cell use. Nat. Mater. 3 , 394-397 (2004).

42. Juarez, R., Concepcion, P., Corma, A. \& Garcia, H. Ceria nanoparticles as heterogeneous catalyst for $\mathrm{CO}_{2}$ fixation by omega-aminoalcohols. Chem. Commun. 46, 4181-4183 (2010).

43. Leyva-Pérez, A., Cómbita-Merchán, D., Cabrero-Antonino, J. R., Al-Resayes, S. I. \& Corma, A. Oxyhalogenation of activated arenes with nanocrystalline ceria. ACS Catal. 3, 250-258 (2013).

44. Tamura, M. \& Tomishige, K. Redox properties of $\mathrm{CeO}_{2}$ at low temperature: the direct synthesis of imines from alcohol and amine. Angew. Chem. Int. Ed. Engl. 54, 864-867 (2015).

45. Schmidt, P. O. et al. Spectroscopy using quantum logic. Science 309, 749-752 (2005).

46. Esch, F. et al. Electron localization determines defect formation on ceria substrates. Science 309, 752-755 (2005).

47. Vilé, G., Colussi, S., Krumeich, F., Trovarelli, A. \& Pérez-Ramírez, J. Opposite face sensitivity of $\mathrm{CeO}_{2}$ in hydrogenation and oxidation catalysis. Angew. Chem. Int. Ed. Engl. 126, 12265-12268 (2014).

48. García-Melchor, M., Bellarosa, L. \& López, N. Unique reaction path in heterogeneous catalysis: the concerted semi-hydrogenation of propyne to propene on $\mathrm{CeO}_{2}$. ACS Catal. 4, 4015-4020 (2014).

49. Vile, G., Bridier, B., Wichert, J. \& Perez-Ramirez, J. Ceria in hydrogenation catalysis: high selectivity in the conversion of alkynes to olefins. Angew. Chem. Int. Ed. Engl. 51, 8620-8623 (2012).

50. Carrasco, J. et al. Molecular-level understanding of $\mathrm{CeO}_{2}$ as a catalyst for partial alkyne hydrogenation. J. Phys. Chem. C 118, 5352-5360 (2014).

51. García-Melchor, M. \& López, N. Homolytic products from heterolytic paths in $\mathrm{H}_{2}$ dissociation on metal oxides: the example of $\mathrm{CeO}_{2}$. J. Phys. Chem. C 118, 10921-10926 (2014).

52. Wischert, R., Laurent, P., Coperet, C., Delbecq, F. \& Sautet, P. $\gamma$-alumina: the essential and unexpected role of water for the structure, stability, and reactivity of "defect" sites. J. Am. Chem. Soc. 134, 14430-14449 (2012).

53. Li, J. et al. Low pressure induced porous nanorods of ceria with high reducibility and large oxygen storage capacity: synthesis and catalytic applications. J. Mater. Chem. A 2, 16459-16466 (2014).

54. Zhang, S., Li, J., Gao, W. \& Qu, Y. Insights into the effects of surface properties of oxides on the catalytic activity of Pd for C-C coupling reactions. Nanoscale 7, 3016-3021 (2015).

55. Tian, Z. et al. Highly sensitive and robust peroxidase-like activity of porous nanorods of ceria and their application for breast cancer detection. Biomaterials 59, 116-124 (2015).

56. Zhang, S. et al. Visible-light-activated Suzuki-Miyaura coupling reactions of aryl chlorides over the multifunctional $\mathrm{Pd} / \mathrm{Au}$ /porous nanorods of $\mathrm{CeO}_{2}$ catalysts. ACS Catal. 5, 6481-6488 (2015).

57. Mai, H.-X. et al. Shape-selective synthesis and oxygen storage behavior of ceria nanopolyhedra, nanorods, and nanocubes. J. Phys. Chem. B 109, 24380-24385 (2005).

58. Wu, Z., Mann, A. K. P., Li, M. \& Overbury, S. H. Spectroscopic investigation of surface-dependent acid-base property of ceria nanoshapes. J. Phys. Chem. C 119, 7340-7350 (2015)

59. Binet, C., Daturi, M. \& Lavalley, J.-C. IR study of polycrystalline ceria properties in oxidised and reduced states. Catal. Today 50, 207-225 (1999). 
60. Nolan, M., Grigoleit, S., Sayle, D. C., Parker, S. C. \& Watson, G. W. Density functional theory studies of the structure and electronic structure of pure and defective low index surfaces of ceria. Surf. Sci. 576, 217-229 (2005).

61. Welch, G. C., Juan, R. R. S., Masuda, J. D. \& Stephan, D. W. Reversible, metal-free hydrogen activation. Science 314, 1124-1126 (2006).

62. Kresse, G. \& Hafner, J. Ab initio molecular-dynamics simulation of the liquid-metal-amorphous-semiconductor transition in germanium. Phys. Rev. B 49, 14251-14269 (1994).

63. Kresse, G. \& Furthmüller, J. Efficiency of ab-initio total energy calculations for metals and semiconductors using a plane-wave basis set. Comp. Mater. Sci. 6, 15-50 (1996).

64. Kresse, G. \& Furthmüller, J. Efficient iterative schemes for $a b$ initio total-energy calculations using a plane-wave basis set. Phys. Rev. B 54, 11169-11186 (1996).

65. Chen, H.-T., Choi, Y. M., Liu, M. \& Lin, M. C. A theoretical study of surface reduction mechanisms of $\mathrm{CeO}_{2}(111)$ and (110) by $\mathrm{H}_{2}$. ChemPhysChem 8, 849-855 (2007).

66. Fernández-Torre, D., Carrasco, J., Ganduglia-Pirovano, M. V. \& Pérez, R. Hydrogen activation, diffusion, and clustering on $\mathrm{CeO}_{2}(111)$ : A DFT $+\mathrm{U}$ study. J. Chem. Phys. 141, 014703 (2014).

67. Metiu, H., Chrétien, S., Hu, Z., Li, B. \& Sun, X. Chemistry of Lewis acid-base pairs on oxide surfaces. J. Phys. Chem. C 116, 10439-10450 (2012).

\section{Acknowledgements}

We acknowledge the financial support from a NSFC Grant 21201138, 21401148, 21603170,91645203 and the National 1000-Plan programme. This work was also funded by the Fundamental Research Funds for the Central Universities under Grant xjj2013102, xjj2013043 and xjj2014064. We thank Professor Suitao Qi at Xi'an Jiaotong University for getting access to the software of Vienna Ab-initio Simulation Package.

The calculations were performed by using supercomputers at Shanghai Supercomputing Center and National Supercomputing Center in Shenzhen.

\section{Author contributions}

S.Z., Z.Q.H., Y.M., C.R.C. and Y.Q. designed the studies and wrote the paper. S.Z., W.G., J.L., F.C. and L.L. performed most of the experiments. Z.Q.H. carried out the DFT calculations. S.Z., Z.Q.H., Y.M., C.R.C. and Y.Q. performed data analysis. All authors discussed the results and commented on the manuscript.

\section{Additional information}

Supplementary Information accompanies this paper at http://www.nature.com/ naturecommunications

Competing interests: The authors declare no competing financial interests.

Reprints and permission information is available online at http://npg.nature.com/ reprintsandpermissions/

How to cite this article: Zhang, S. et al. Solid frustrated-Lewis-pair catalysts constructed by regulations on surface defects of porous nanorods of $\mathrm{CeO}_{2}$. Nat. Commun. 8, 15266 doi: 10.1038/ncomms15266 (2017)

Publisher's note: Springer Nature remains neutral with regard to jurisdictional claims in published maps and institutional affiliations.

(c) (i) This work is licensed under a Creative Commons Attribution 4.0 International License. The images or other third party material in this article are included in the article's Creative Commons license, unless indicated otherwise in the credit line; if the material is not included under the Creative Commons license, users will need to obtain permission from the license holder to reproduce the material. To view a copy of this license, visit http://creativecommons.org/licenses/by/4.0/

(C) The Author(s) 2017 